\title{
Complications of penile self-injections: investigation of 680 patients with complications following penile self-injections with mineral oil
}

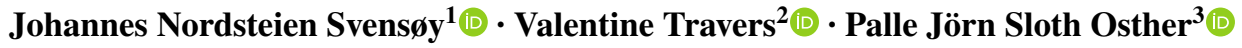

Received: 13 September 2017 / Accepted: 20 October 2017 / Published online: 28 October 2017

(C) The Author(s) 2017. This article is an open access publication

\begin{abstract}
Objective Penile implants and injection of foreign materials have been described in texts like Kama Sutra for more than 1500 years, and are still being practiced around the world. The extent of this practice is unknown, and the documentation available today only scratches the surface. This study investigates and documents the complications after penile self-injections at the Mae Tao Clinic. To our knowledge, this study represents the largest series of patients representing complications to penile self-injections.

Study design Retrospective study.

Methods We investigated data on 680 patients admitted with penile self-injections during a 5-year period. Data were studied for general patient data, symptoms, time of injection, and treatment.

Results Age at admittance ranged from 17 to 68 with a mean age of 32 years. Time between injection and presentation was registered with a mean of 36.7 months, over half presented with complications within 1 year. Most frequent complications were penile pain (84\%), swelling (82.5\%), induration $(42.9 \%)$, purulent secretion $(21.8 \%)$, and ulceration (12.8\%). Of the 680 patients, 507 (74.6\%) underwent surgical treatment (503 excision and 4 circumcision), while $173(25.4 \%)$ were treated conservatively.
\end{abstract}

Johannes Nordsteien Svensøy and Palle Jörn Sloth Osther authors contributed equally to this work.

Johannes Nordsteien Svensøy

JohannesSvensoy@gmail.com

Lege Svensøy, Oslo, Norway

2 Centre de santé, Seine-Saint-Denis, Saint-Denis, France

3 Urological Research Center (URC), Department of Urology, Lillebaelt Hospital, Fredericia, Denmark
Conclusion Our data suggest that penile self-injections with mineral oil are more prevalent in certain areas than previously acknowledged. In 5 years, more than 680 patients presented with complications to penile self-injections, of which $75 \%$ needed surgical intervention, mainly in the form of radical excision of the lesions followed by skin grafting. Preventive measures to this physically and psychologically devastating problem are highly warranted.

Keywords Penile self-injection · Self-administration · Penile injection · Penile augmentation · Paraffinoma . Granuloma $\cdot$ Lipogranuloma $\cdot$ Mineral oil $\cdot$ Penile induration $\cdot$ Penile swelling $\cdot$ Myanmar $\cdot$ Mae Tao Clinic

\section{Background}

Penile implants and injection of foreign materials have been described in texts like Kama Sutra for more than 1500 years. Implants of glass, stone, bullets, ivory, gems, gold, plastic and other solid objects, as well as injections with silicone, paraffin, Vaseline, petroleum jelly [1], cod liver oil [2], nandrolone decanoate [3], waxes, and mineral oils for penile augmentation have been described in the literature.

Robert Gersuny was the first to describe injections of mineral oil as a medical procedure in 1899 , injecting Vaseline to substitute the loss of testicles after tuberculosis epididymitis [4]. Since then mineral oil injections have been used for a wide range of cosmetic purposes, i.e., cleft palate, wrinkles, face deformities, baldness, and muscle, breast and penile augmentation [5, 6]. Heidingsfeld presented the first report of adverse effects of human body oil injections in 1906, describing disfiguring subcutaneous nodules after paraffin injections for facial wrinkles [4, 7]. In 1917 Fermiet and Fermiet reported similar tumours occurring weeks to 
years after injection of mineral oil [8]. After several reports of serious adverse effects, these treatment modalities were omitted in traditional medicine. Nevertheless, they are still used by non-medical personnel or as self-injections mostly for cosmetic purposes.

Penile self-injections are performed with the purpose of increasing the size of the penis. Most often mineral oils or mineral oil-like substances are used for this purpose. Complications occur due to the fact that human tissue lacks the enzymes to metabolize interstitial exogenous oils $[9,10]$. This, results in the formation of a paraffinoma, also referred to as oleoma or sclerosing lipogranuloma, presenting as a characteristic histological lesion. Although there are no exact statistics available, literature suggest the procedure to be more commonly performed in Asia and Eastern Europe. An earlier study of 639 Burmese fishermen in Thailand revealed a prevalence of $7.5 \%$ [11]. Another study among Hungarian prisoners found that $15.7 \%$ had performed penile self-injections [12]. The aim was to investigate and document complications after penile self-injections to increase the knowledge and raise awareness about complications to established health-care takers, risk groups, and to the general population in a high prevalence area.

\section{Materials and methods}

The study was performed at the Mae Tao Clinic, which is located on the Thailand-Myanmar border. It annually treats more than 100,000 patients from both sides of the border with free health-care [13]. The clinic was founded by Dr. Cynthia Maung in 1989. Data were collected from patients at the Surgery and Trauma department at the Mae Tao Clinic.

Data on penile self-injections were sampled retrospectively to explore prevalence, risks, and treatment modalities for management of complications. All data were analysed anonymously.

All registered cases of penile injections at the Mae Tao Clinic from 2010 through 2014 were initially included, comprising a total of 899 registrations (Fig. 1). The list of patients was manually checked for errors and double entries (patients registered more than one time); 130 double entries were found and removed. The main reason for double entries was re-registration, when patients returned for skin grafts after excision, or when conservative treatment regimens were converted to surgery due to lack of improvement.

769 registration papers were collected from the archive and further investigated: 56 were wrongly registered as penile injections, and 30 registration papers were missing; 3 patients were excluded as the dates of complication presentation were outside the study period (2010-2014).

Finally, 680 patients were included and their registration papers studied for 20 predefined variables of complaints

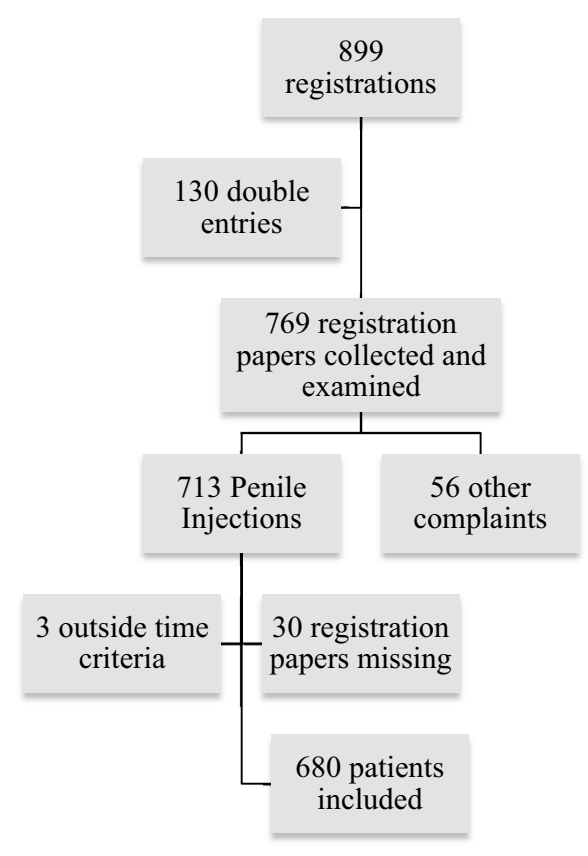

Fig. 1 Included patients from the registration at the Mae Tao Clinic

(Table 1). Additionally, age, weight, address, ethnicity, time of injection and treatment of complication were also registered. The 680 patients were grouped according to main complication into Mild, Moderate, Severe, and Life Threatening (Table 1). All data were anonymously registered in SPSS v.22.

\section{Results}

The mean age among the 680 patients was 32 years, ranging from 17 to 68 years (for distribution see Fig. 2). There was no significant difference in symptoms presented or treatment given in regard to age.

Time between injection and presentation of symptoms was registered in 643 patients with a mean of 36.7 months, ranging from a few days to 30 years: 346 (53.8\%) presented to the Mae Tao Clinic with complications within 1 year after injection, $72(11.2 \%)$ between 1 and 2 years, 47 (7.3\%) between 2 and 3 years, 31 (4.8\%) between 3 and 4 years, and $147(22.9 \%)$ presented with complications more than 4 years after injection. The age of the patient at the time of injection ranged between 13 and 66 years (mean 29 years).

The most frequently reported symptoms were penile pain, swelling, induration, purulent secretion, and ulceration (Fig. 3, Table 2). Of these, pain was the most prominent, covering intermittent pain, pain during erection, and chronic pain. 
Table 1 Predefined variables of complaints

Fig. 2 Age distribution of patients presenting with complications following penile self-injections

Fig. 3 Presenting symptoms of penile self-injections

\begin{tabular}{llll}
\hline Mild & Moderate & Severe & Life threatening \\
\hline Penile pain & Phimosis & Induration & Fournier's gangrene \\
Swelling & Ulceration & Necrosis & Sepsis \\
Penile erythema & Purulent secretion & & \\
Itching at injection area & Pale penile skin colour change & & \\
Discharge & Dysuria & & \\
& Fever & & \\
& Atrophy & & \\
& Recurrent bleeding & & \\
\hline
\end{tabular}
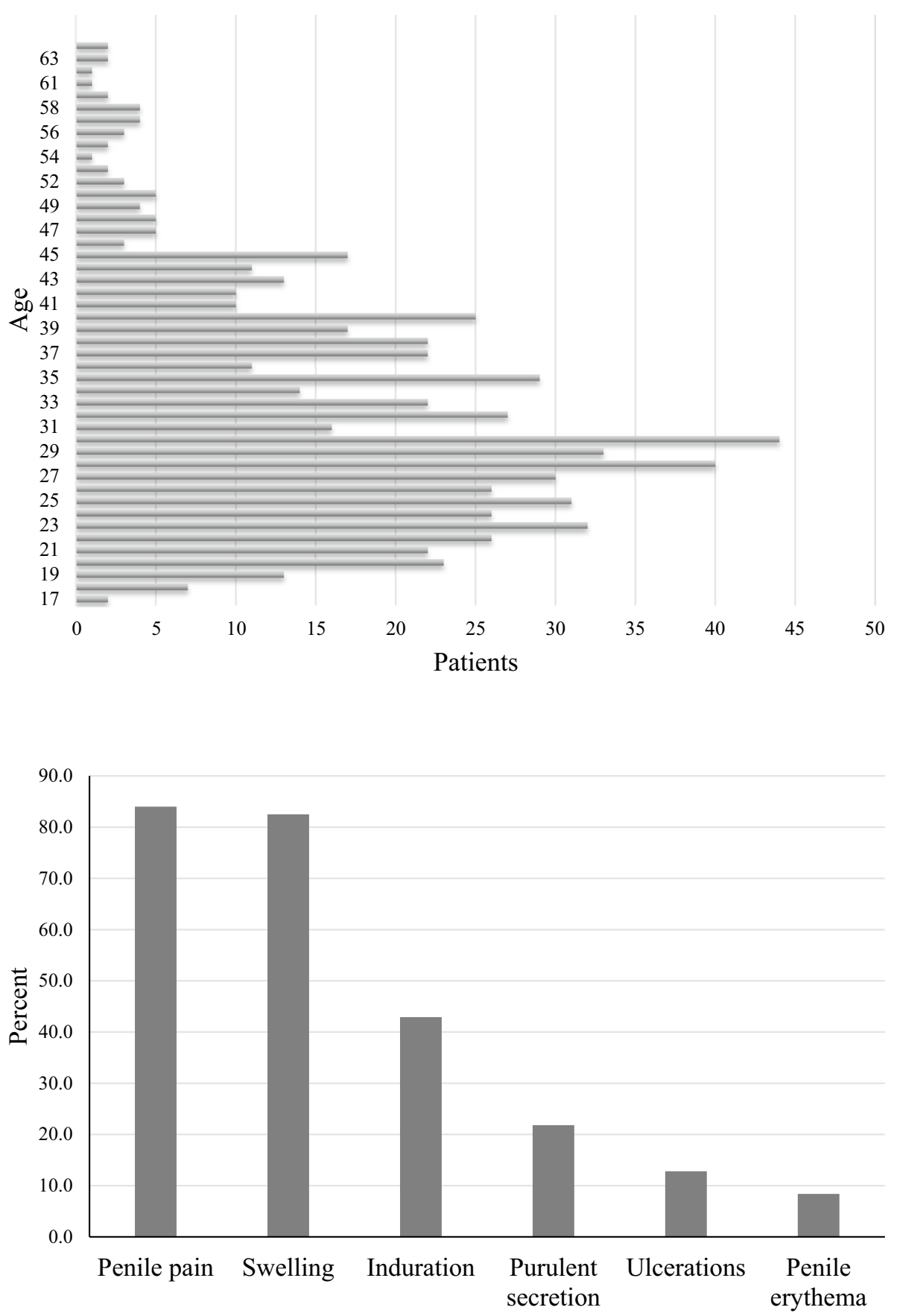
Table 2 Presenting symptoms of penile self-injections

\begin{tabular}{lll}
\hline Symptom & Patients $(N=680)$ & Percent \\
\hline Penile pain & 571 & 84 \\
Swelling & 561 & 82.5 \\
Induration & 292 & 42.9 \\
Purulent secretion & 148 & 21.8 \\
Ulcerations & 87 & 12.8 \\
Penile erythema & 57 & 8.4 \\
\hline
\end{tabular}

Table 3 Treatment performed at the Mae Tao Clinic

\begin{tabular}{lll}
\hline & Frequency & Percent \\
\hline Surgical treatment & 507 & 74.6 \\
Conservative treatment & 173 & 25.4 \\
Total & 680 & 100 \\
\hline
\end{tabular}

Moderate complications consisted of phimosis, ulcers, and purulent secretion (Table 1). Ulcers presented as chronic wounds. Of 87 patients with ulcerations, 42 had purulent secretion. Patients with ulcers had a mean presentation time of 48 months after injection compared to a mean of 36.7 months for the whole group. Atrophy of the skin was seen in $9(1.3 \%)$ patients. Voiding complaints was seen in $28(4.1 \%)$, including dysuria and stranguria; $35(5.1 \%)$ of the patients had pale penile skin colour changes. Recurrent bleeding was reported in 3 patients.

Severe induration, which was seen in 292 (42.9\%) patients, was grouped as a severe complication, since this finding most often needs surgical correction. Induration was noted as hard firm masses, which in the literature has been attributed to lipogranulomas. Necrosis was seen in 11 (1.6\%) patients, 2 of which was admitted short time after injecting mineral oil ( 1 and 3 weeks).

Mode of treatments were grouped into conservative 173 (25.4\%), and surgical 507 (74.6\%) (Table 3). Conservative treatment consisted of dressing, and/or antibiotics, and/or painkillers. It is important to point out that the conservative treatment group also included patients reluctant to surgical treatment. Surgical treatment included complete excision of involved tissue. In 4 cases circumcision was sufficient to remove the affected lesion. All complete excisions were followed by a split thickness skin graft from the anterior thigh after 3 to 10 days. Surgical excision was done under penis block. General anaesthesia was not available at the Mae Tao Clinic.

During the 5-year study period, the number of patients presenting with complications after penile self-injections increased; however, the percentage of conservative versus surgical treatments largely remained the same (Fig. 4, Table 4).

The total patient load of The Trauma and Surgical Department at the Mae Tao Clinic has decreased during the latest years, while the number of cases of penile selfinjections has increased (Fig. 4).
Fig. 4 Development of treatments during study period

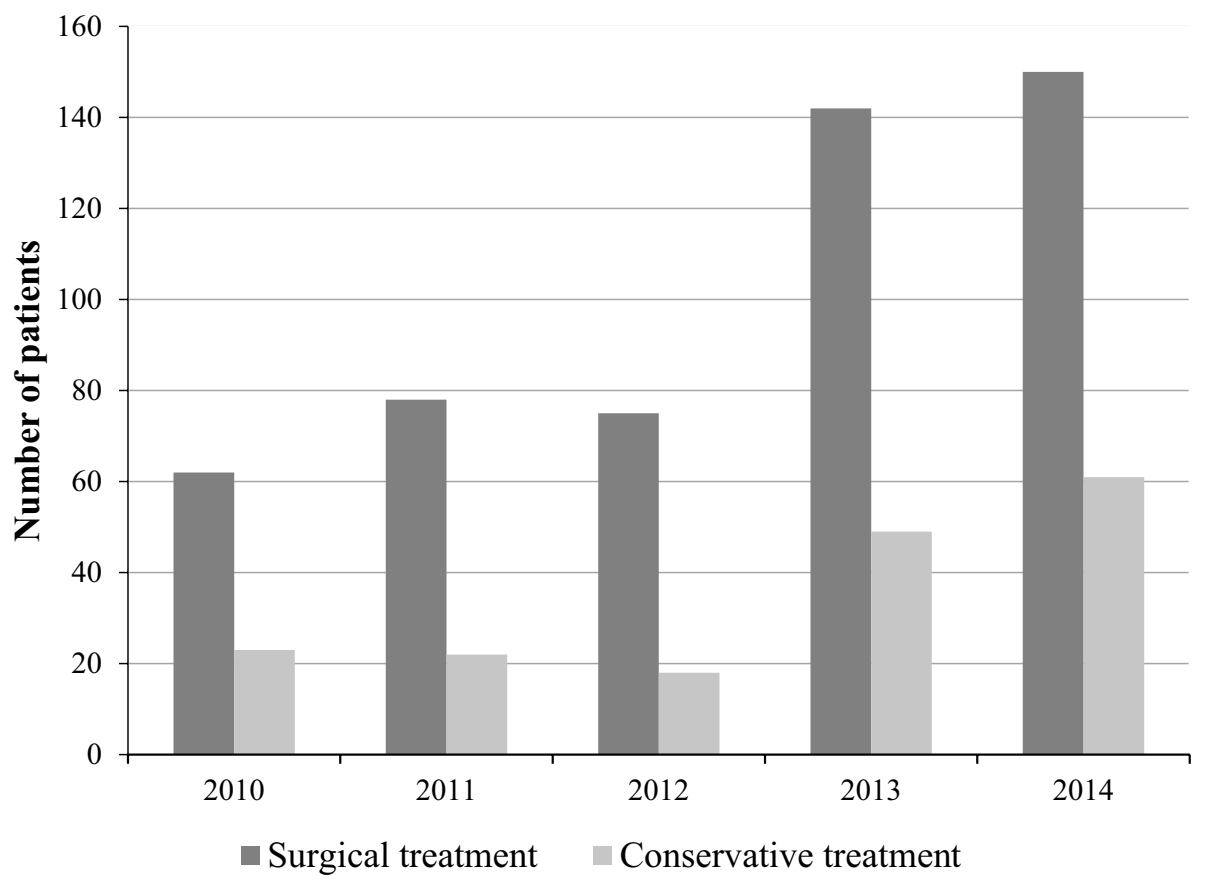


Table 4 Development of treatments during study period in numbers

\begin{tabular}{lcc}
\hline Year & Patients & Percent \\
\hline 2010 & & \\
Surgical treatment & 62 & 72.9 \\
Conservative treatment & 23 & 27.1 \\
Total & 85 & 100 \\
2011 & & \\
Surgical treatment & 78 & 78 \\
Conservative treatment & 22 & 22 \\
Total & 100 & 100 \\
2012 & & \\
Surgical treatment & 75 & 80.6 \\
Conservative treatment & 18 & 19.4 \\
Total & 93 & 100 \\
2013 & & \\
Surgical treatment & 142 & 74.3 \\
Conservative treatment & 49 & 25.7 \\
Total & 191 & 100 \\
2014 & & \\
Surgical treatment & 150 & 28.9 \\
Conservative treatment & 61 & 100 \\
Total & 211 & \\
\hline
\end{tabular}

\section{Discussion}

To our knowledge this study represents by far the largest series of complications to penile self-injections. We want to stress the importance of knowing symptoms related to penile self-injections, as patients presenting complications may be reluctant to inform about their previous self-injection. Taboo-illegal status of the procedure and expensive treatment not covered by health insurance-might be some of the reasons. Mae Tao Clinic offers free health-care to all patients and has established a renowned experience treating penile self-injections; this is probably the reason for the high number of cases seeking help at the clinic.

At the time of presentation, nearly half of the included patients had severe complications in the form of indurated penile skin. We did not have the possibility to do histological examination of excised tissue, but macropathological examination done during surgery correlates with earlier studies documenting lipogranulomas as firm, disfigured, subcutaneous masses $[5,9,14,15]$. In addition to these macropathological findings, skin colour change has been reported in a few cases in the available literature [14], and seen in 35 (5.1\%) of our patients. Atrophy of the skin may be the underlying cause of the skin colour change (Fig. 5).

Some of our findings differ from earlier reports. Pain and swelling was seen in more than $80 \%$ of our patients. In an investigation of Korean prisoners $(N=357)$, only $15.5 \%$ reported pain [16]. We included painful erections in our

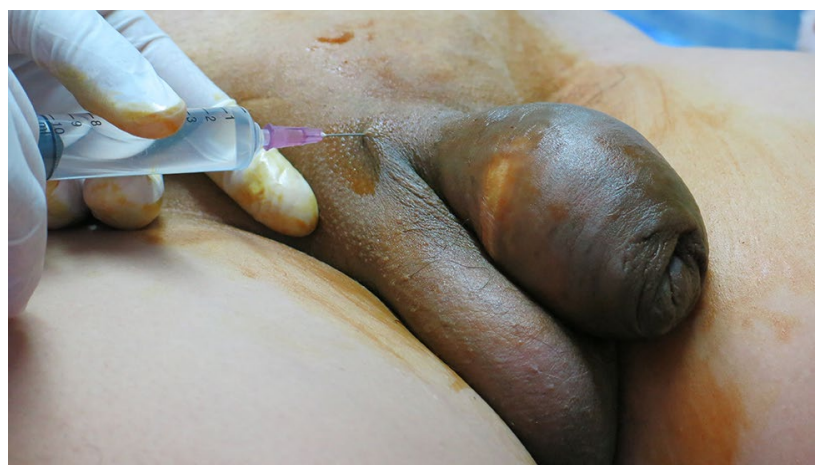

Fig. 5 Pale penile skin colour change presented at the Mae Tao Clinic

pain category, which may explain the higher incidence of reported pain in our series. Furthermore, differences in pain score may be attributed to differences in the oil material injected. In another study of a prison population [12], in which 76 had performed penile self-injections with Vaseline (petrolatum), 17 (22.4\%) reported pain, while as many as $40(52.6 \%)$ had ulcerations. Compared to $12.8 \%$ in our findings (Figs. 6, 7). The high incidence of ulcers in the prison population may be explained by a setting of poor hygiene. In the earlier mentioned prison population described by Moon et al. [16] $(N=357)$, skin necrosis was reported in as many as $11.1 \%$. It may be questioned if this is a direct result of penile injection or also related to lack of sterile equipment and poor hygiene.

Time of symptom presentation at the Mae Tao Clinic varied tremendously, ranging from a few days to 30 years after injection. This is in accordance with a case study by Eandi et al. [17], documenting a latency of complications of nearly 40 years. In two other studies, reporting on 26 [14] and 23 [18] cases, mean time from injection to presentation was 18.5 and 12.6 months, respectively. It has to be taken into consideration that the time between injection and hospitalization is not necessarily identical to the time between injection and initiation of complications. The majority of the men might be suspected to have been reluctant to seek medical help early in the course of the disease, due to the special taboo nature of this complex disease.

When the first case of complications following penile self-injection was seen at the Mae Tao Clinic in 2001, the clinic had no experience with surgical treatment of these complications. The surgical staff improvised with different kinds of conservative (antibiotics and/or dressings and/or analgesics) and surgical treatments (both partly removal and full excision of involved skin), but quickly learned that radical surgical excision of the involved skin followed by skin graft coverage was the only permanent reliable treatment (Fig. 8). This was confirmed in other published series $[1,2,19]$. Radical excision is recommended due to 


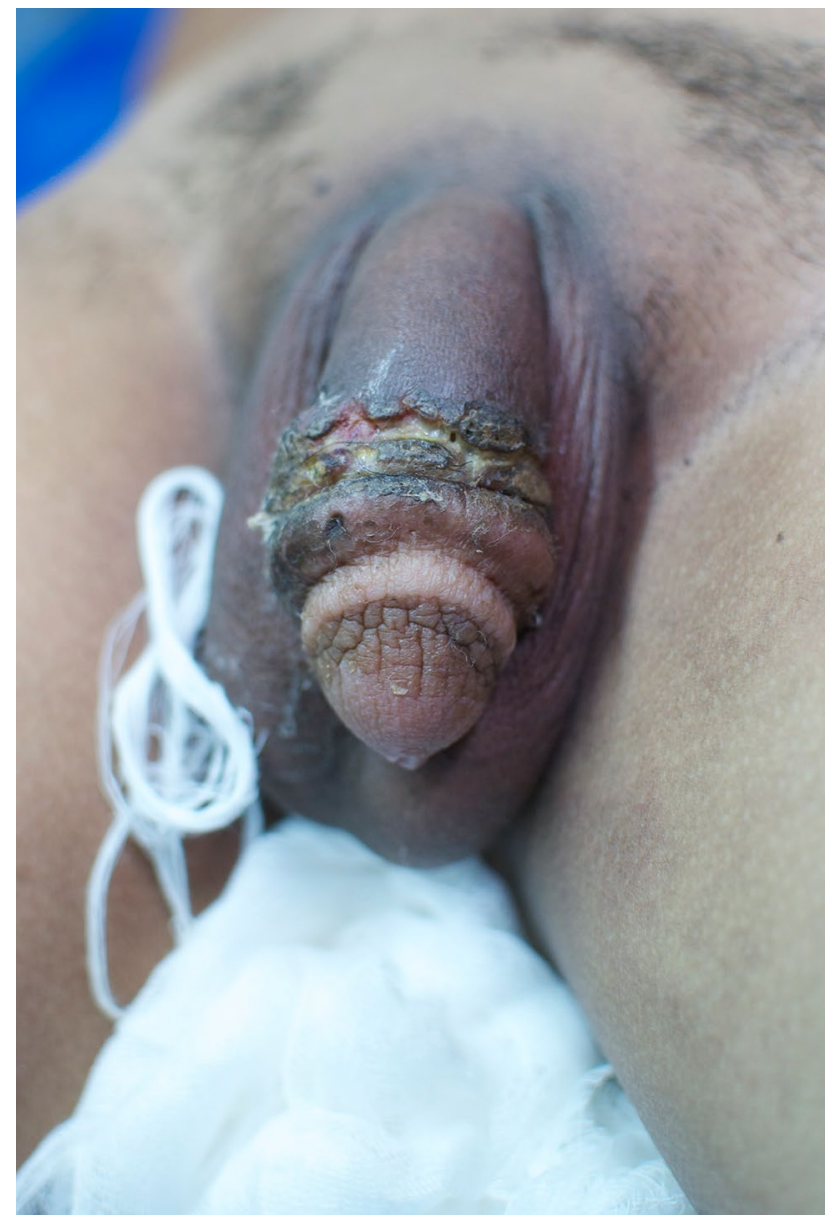

Fig. 6 Ulcer presented at the Mae Tao Clinic

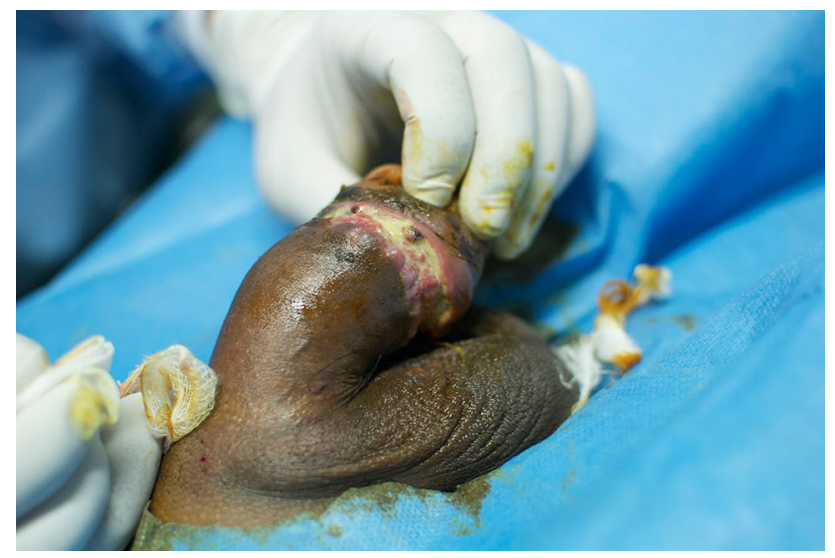

Fig. 7 Ulcer presented at the Mae Tao Clinic

a high risk of subsequent serious complications, if not all foreign-body liquid is removed $[6,18,20]$. Skin coverage solutions involve split thickness skin graft, use of the prepuce (if not involved), scrotal skin flap [14, 21, 22], and Cecil's inlay operation $[10,14]$. In the two-staged Cecil's

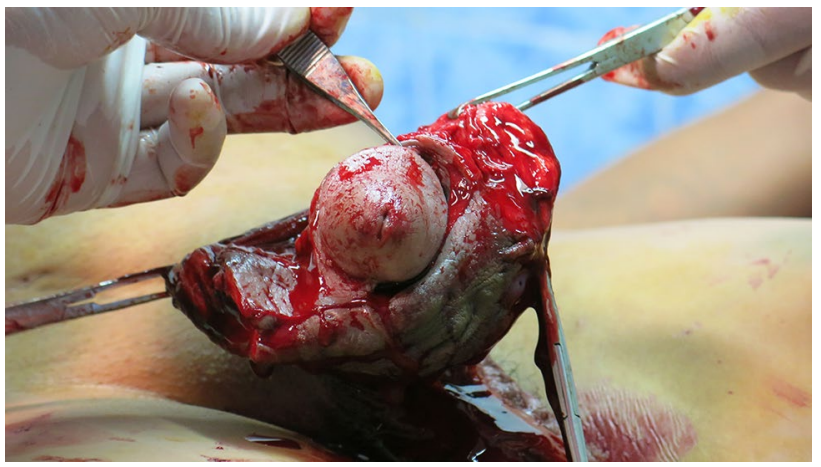

Fig. 8 Full excision performed at the Mae Tao Clinic

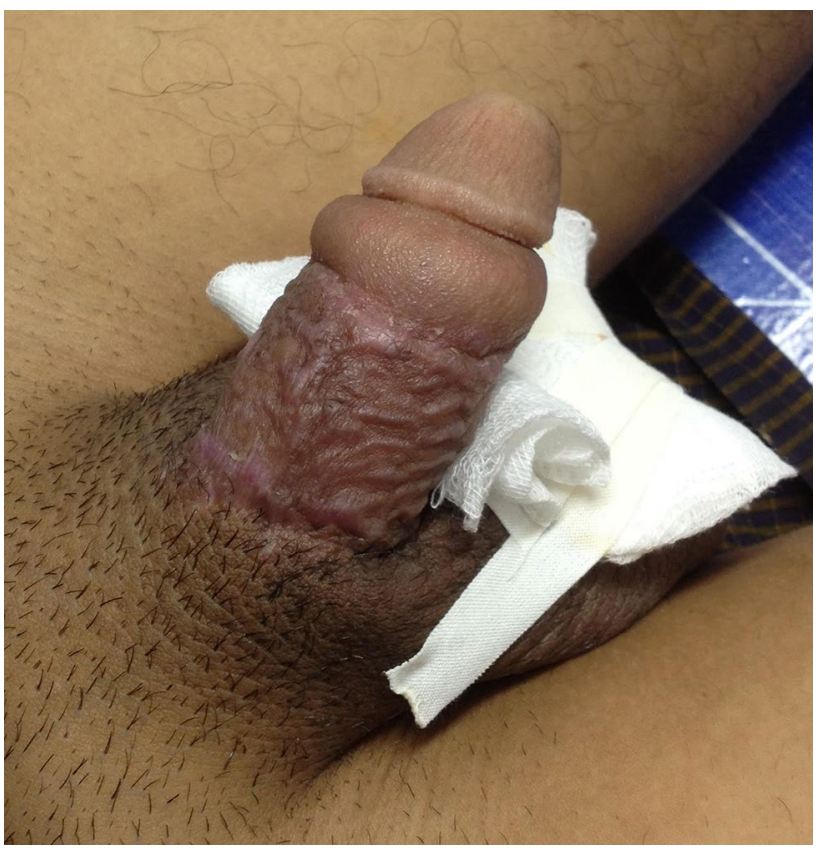

Fig. 9 Excision and graft treatment performed at the Mae Tao Clinic

operation the denuded penis is buried in scrotum and penoplasty is carried out 2-3 months later. Split thickness skin graft as used at the Mae Tao Clinic is a relatively simple technique, which has demonstrated good graft survival in the present series [6] (Fig. 9). Regardless of treatment option (conservative or surgical treatment) nearly all our patients were treated with antibiotics [637 of 680 patients (93.7\%)]. It is the experience from the Mae Tao Clinic that antibiotics are mandatory for controlling secondary infections and as prophylaxis during surgical treatment. Since no follow-up data were available, we are not able to draw conclusions on treatment options. Even if failing as a permanent treatment, more research is needed on conservative options for patients that are reluctant to surgery for religious or subjective reasons, or when surgery is not a possible option [23]. There was no economical bias in 


\section{How does a normal penis work?}
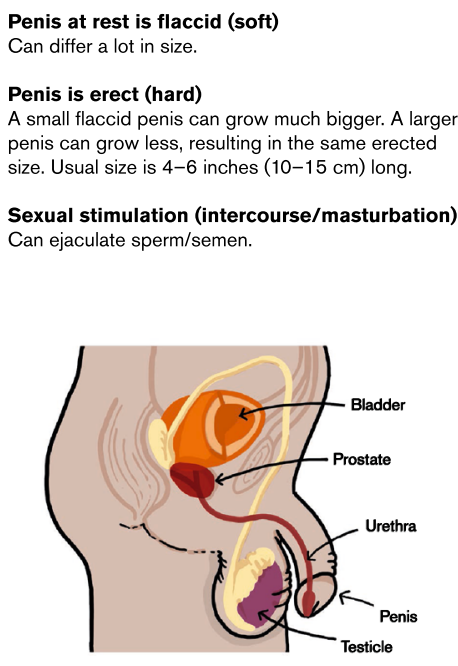

What can make penis erection difficult?

- Not good physical or mental health

- Smoking

- Stress

- Heart diseases

- Alcohol or drug abuse

- Injection of oils into the penis

\section{Because of known complications, do not do penis self- injection or implants.}

\author{
It is not safe even if an experienced person \\ does the injection. \\ No materials/oils are safe for injection in \\ the penis.
}
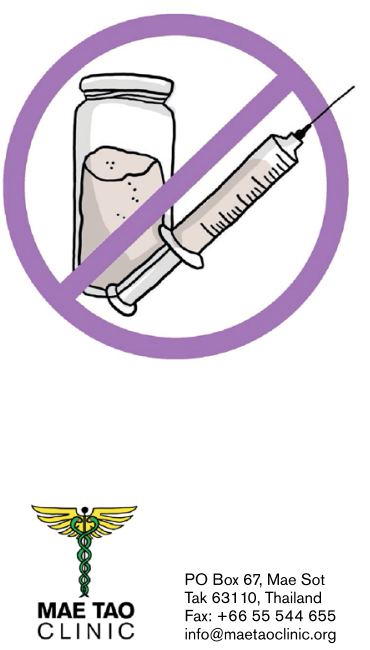

PO Box 67, Mae Sot Fax: +66555544655 Fax: +6655544655
info@maetaoclinic.org

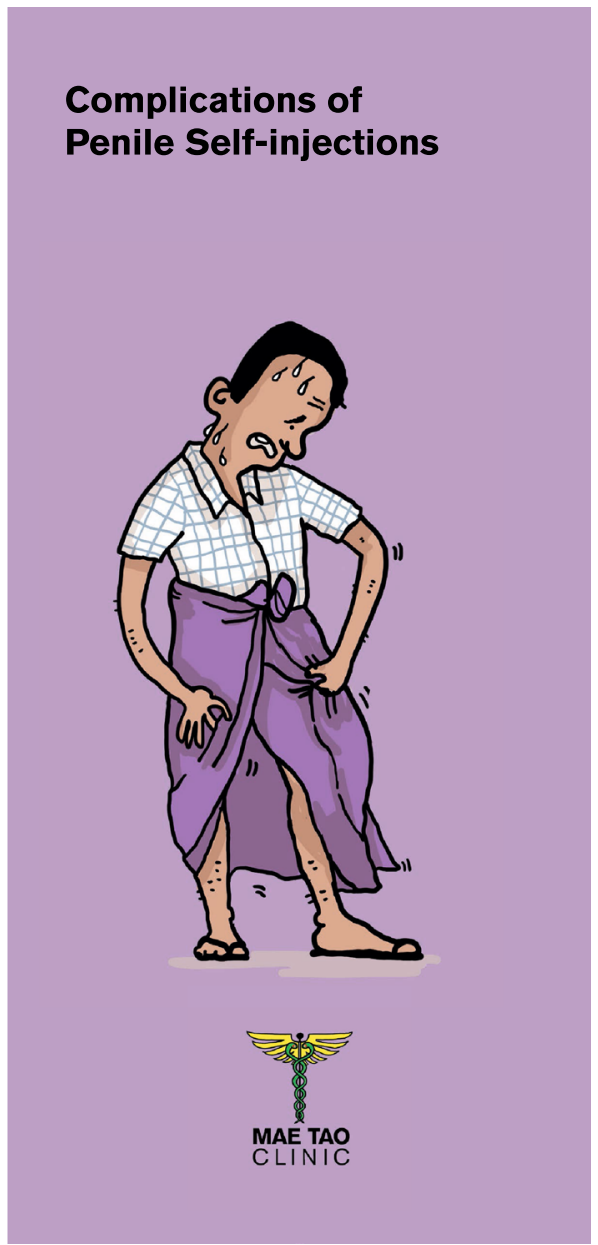

Fig. 10 Information leaflet on complications of penile self-injections (English version)

choosing either conservative or surgical treatment options at the Mae Tao Clinic.

For prevention purposes, we registered the address of the patients to see if the frequency of injections was higher in certain areas. However, because some of the patients were immigrant workers and refugees, there was no consistency in patients giving home or temporary work addresses. Furthermore, many of the patients stayed undocumented in Thailand, which might have made them more reluctant giving their true address. What may be concluded from our observations is that, patients performing penile self-injections in this area obviously came from different locations and populations, and not just from one homogenous group as has been suggested in previous studies (e.g., fishermen [11], and prisoners [12, 16, 18]). Furthermore, concerning prevention, special consideration must be taken, as a wide spread informingcampaign in the general population potentially could lead to increased use of penile self-injections. Experience tells us that many of the patients got introduced to and underwent the procedure performed by non-medical personnel based on recommendations by acquaintances (data from interviews with surgical staff at the Mae Tao Clinic).

Risky sexual behaviour has been associated with penile oil self-injections in a study by Ohnmar et al. among Myanmar fishermen in Thailand $(N=48)$ [11]: $70.8 \%$ having had sex with commercial sex workers during the last year compared to $35.9 \%$ of men without injections $(N=440)$. Additionally, use of condoms was significantly lower in those with injections; only $8 \%$ always using condoms compared to $69 \%$ in the population without injections [11]. We did not find any signs suggesting that the patients studied at the Mae Tao Clinic were involved in risky sexual behaviour such as a higher prevalence of symptoms related to sexual transmitted diseases.

Although this study has several limitations, including its retrospective design and the lack of systematic follow-up data, it is obvious that, penile oil self-injections do have serious health problems, and that the extent of the practice is probably more widespread in unlit areas than previously acknowledged. Our data should result in initiation of prevention campaigns directed both at risk 


\section{What is penis self-injection?}

It means to inject/put materials such as coconut oil, palm oil, other liquids, glass-ball or objects into the skin of the penis.
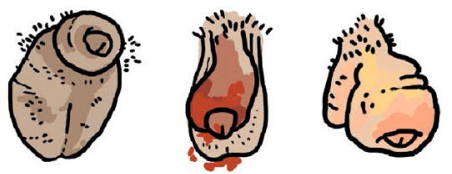

Injections or implants can cause

many problems, such as:

- Not healthy body image

- Family and social problems

- Cost of treatment

Short term problems:

- Getting infections such as HIV-AIDS from injection

- Oil leak to testicle causing pain and problems

- Wounds or infections difficulty to heal

- Painful sexual intercourse (also for partner)

- Loss of penis function

Long term problems:

- The skin becomes hard and cause penis pain

- Pain or hard to urinate

- Penis cancer

- Scar, or loss of penis

\section{What is the treatment?}

Seek medical care, for example at Mae Tao Clinic, for the possibility of repairing surgery.

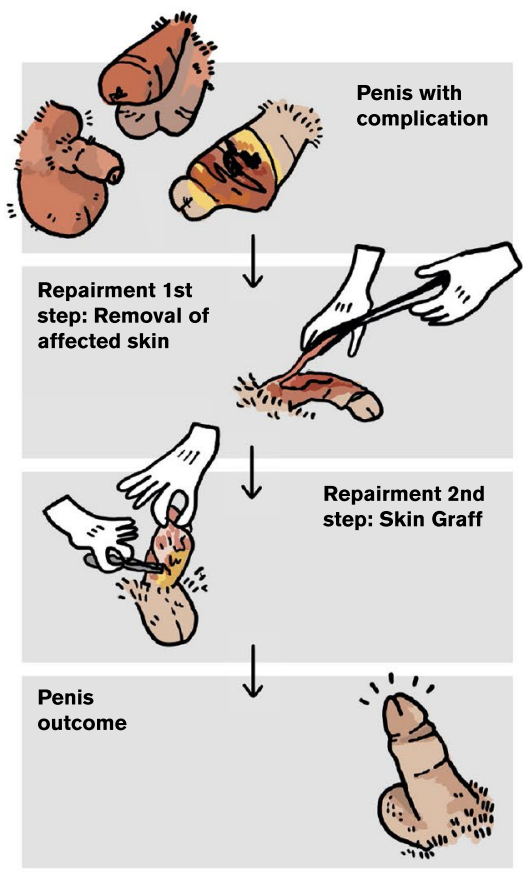

\section{How to increase sexual pleasure?}

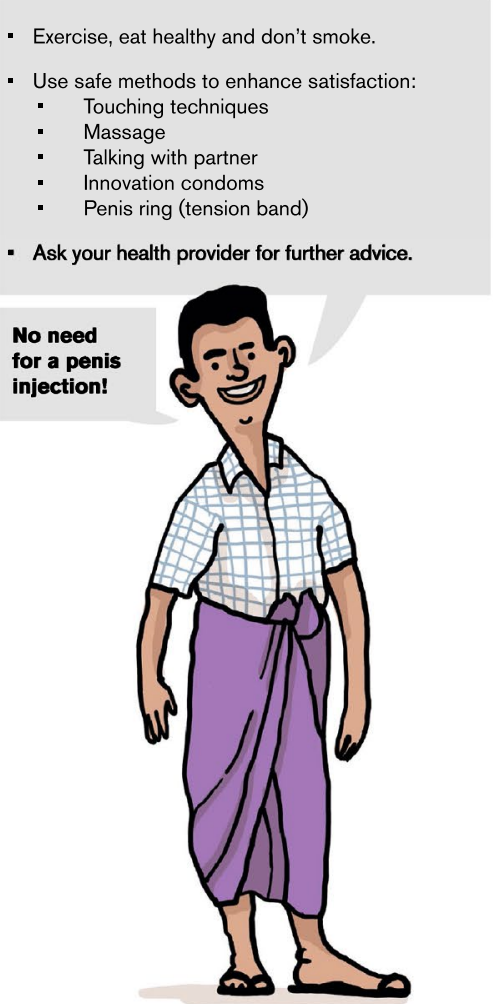

Fig. 10 (continued)

populations and health-care professionals. Education of the latter about these practices and their debilitating and destructive consequences is essential, since patients often do not inform about the practice at their initial contact. Additionally, it is important to acknowledge and disseminate to risk populations that even severe complications may be treated successfully with radical excision of the lesions and skin grafts. Based on our data, prevention has been initiated in the Mae Tao Clinic (Fig. 10).

\section{Conclusion}

Our data suggest that penile self-injections with mineral oil are more prevalent in certain areas than previously acknowledged. Our retrospective study showed that in 5 years more than 680 patients presented with complications to penile self-injections at the Mae Tao Clinic, of which $75 \%$ needed surgical intervention, mainly in the form of radical excision of the lesions followed by skin grafting. Preventive measures to this physically and psychologically devastating problem are highly warranted.
Acknowledgments We thank the Registration and the Trauma and Surgical department at Mae Tao Clinic for answering questions and providing valuable clinical information. Information leaflet made by illustrator Rán Flygenring (Fig. 10).

Author contributions JNS performed project development, data collection, data analysis, and manuscript writing. VT helped in local project development, and manuscript editing. PJSO contributed to project development, and performed manuscript writing and editing.

Compliance with ethical standards

Conflict of interest The authors declare that they have no conflict of interest.

Ethical approval The study was approved by the $\mathrm{CAB}$ (Community Advisory Board) of the Mae Tao Clinic. All data were analyzed anonymously with only patient numbers as identification.

Informed consent The informed consent was waived in view of the retrospective and anonymous nature of the study.

Funding This study was not funded. 
Open Access This article is distributed under the terms of the Creative Commons Attribution 4.0 International License (http://creativecommons.org/licenses/by/4.0/), which permits unrestricted use, distribution, and reproduction in any medium, provided you give appropriate credit to the original author(s) and the source, provide a link to the Creative Commons license, and indicate if changes were made.

\section{References}

1. Santucci RA, Zehring RD, McClure D (2000) Petroleum jelly lipogranuloma of the penis treated with excision and native skin coverage. Urology 56:331

2. Al-Ansari AA, Shamsodini A, Talib RA et al (2010) Subcutaneous cod liver oil injection for penile augmentation: review of literature and report of eight cases. Urology 75(5):1181-1184

3. Balighi K, Farsinejad K, Naraghi ZS et al (2008) Paraffinoma and ulcer of the external genitalia after self-injection of nandrolone. Int J Dermatol 47(10):1092-1094

4. O'Rourke MG (1967) Lipogranulomata of male genitalia. Br J Urol 39(4):426-430

5. Cohen JL, Keoleian CM, Krull EA (2001) Penile paraffinoma: self injection with mineral oil. J Am Acad Dermatol 45:222-224

6. Bjurlin MA, Carlsen J, Grevious M et al (2010) Mineral oilinduced sclerosing lipogranuloma of the penis. J Clin Aesthet Dermatol 3(9):41-44

7. Stewart RC, Beason ES, Hayes CW (1979) Granulomas of the penis from self-injections with oils. Plast Reconstr Surg 64(1):108-111

8. Steffens J, Kosharskyy B, Hiebl R et al (2000) Paraffinoma of the external genitalia after autoinjection of vaseline. Eur Urol 38:778-781

9. Francis J, Poh Choo Choo A, Wansaicheong Khin-Lin G (2014) Ultrasound and MRI features of penile augmentation by "Jamaica Oil" injection. A case series. Med Ultrason 16(4):372-376

10. Oñate Celdrán J, Sanchez Rodríguez C, Tomás Ros M et al (2012) Penile paraffinoma after subcutaneous injection of paraffin.
Treatment with a two step cutaneous plasty of the penile shaft with scrotal skin. Arch Esp Urol 65(5):575-578

11. Ohnmar, Geater AF, Winn T et al (2009) Penile oil injection, penile implantation and condom use among Myanmar migrant fishermen in Ranong, Thailand. Sex Health. 6(3):217-221

12. Rosecker Á, Bordás N, Pajor L et al (2013) Hungarian "jailhouse rock": incidence and morbidity of Vaseline self-injection of the penis. J Sex Med 10(2):509-515. doi:10.1111/j.1743-6109.2012.02886.x

13. Mae Tao Clinic, official web page. http://maetaoclinic.org/aboutus/history/. Accessed 2015 June

14. Lee T, Choi HR, Lee YT, Lee YH (1994) Paraffinoma of the penis. Yonsei Med J 35:344-348

15. Foxton G, Vinciullo C, Tait CP et al (2011) Sclerosing lipogranuloma of the penis. Australas J Dermatol 52(3):e12-e14

16. Moon DG, Yoo JW, Bae JH et al (2003) Sexual function and psychological characteristics of penile paraffinoma. Asian J Andro. 5:191-194

17. Eandi JA, Yao AP, Javidan J (2007) Penile paraffinoma: the delayed presentation. Int Urol Nephrol 39(2):553-555

18. Pehlivanov G, Kavaklieva S, Kazandjieva J et al (2008) Foreignbody granuloma of the penis in sexually active individuals (penile paraffinoma). Eur Acad Dermatol Venereol 7:845-851

19. Rosenberg E, Romanowsky I, Asali M et al (2007) Three cases of penile paraffinoma: a conservative approach. Urology. 70(2):372. e9-372.e10

20. Karakan T, Ersoy E, Hasçiçek M et al (2012) Injection of vaseline under penis skin for the purpose of penis augmentation. Case Rep Urol 2012:510612

21. Jeong JH, Shin HJ, Woo SH et al (1996) A new repair technique for penile paraffinoma: bilateral scrotal flaps. Ann Plast Surg 37(4):386-393

22. Angspatt A, Pungrasmi P, Jindarak S et al (2009) Bilateral scrotal flap: pedicle and dimension of flap in cadaveric dissections. J Med Assoc Thai 92(10): 1313-1317

23. Zickerman PM, Ratanawong C (2007) Penile oleogranuloma among Wisconsin Hmong. WMJ 106(5):270-274 